\title{
Peluang dan Tantangan Pengembangan Pariwisata di Kawasan Cagar Budaya Keraton Kasunanan Surakarta
}

\author{
RR. Erna Sadiarti Budiningtyas ${ }^{1)}$, H. Muhammad Sirod ${ }^{2)}$ \\ Akademi Bahasa Asing St. Pignatelli Surakarta 1,2) \\ J. Duwet Raya No 1, Karangasem, Laweyan, Surakarta \\ E-mail: sabinaerna70@gmail.com
}

\begin{abstract}
Abstrak
Kawasan cagar budaya Keraton Kasunanan Surakarta yang disebut Baluwarti merupakan kawasan permukiman tradisional yang banyak dihuni oleh abdi dalem dan sentana dalem Keraton Kasunanan Surakarta. Menyadari potensi budaya yang dimiliki, masyarakat berupaya untuk mengembangkan pariwisata. Akan tetapi sudah satu dekade, usaha tersebut belum juga memberikan hasil nyata. Penelitian ini dilakukan dengan tujuan untuk menganalisis peluang dan tantangan pengembangan pariwisata di kawasan permukiman yang berada dalam pengaruh penguasa lokal tradisional. Pendekatan kualitatif digunakan untuk mendapatkan data mendalam melalui wawancara, pengamatan, dan dokumentasi. Pemilihan narasumber dilakukan dengan teknik snowball purposive. Analisis data dilakukan secara deskriptif analitis Miles dan Huberman. Penelitian ini menunjukkan bahwa sebagai permukiman yang berada di kawasan cagar budaya Keraton Kasunanan, Baluwarti memiliki banyak potensi budaya. Namun norma-norma dan pandangan budaya yang melekat kuat dalam diri masyarakat Baluwarti terhadap tatanan budaya keraton, menyebabkan pariwisata sulit berkembang di Baluwarti. Masyarakat memerlukan keterbukaan pihak Keraton sebagai panutan untuk bersama-sama membangun pariwisata Baluwarti agar Keraton dan masyarakat mendapatkan manfaat pariwisata.
\end{abstract}

Kata kunci: Baluwarti, Kawasan Cagar Budaya, Keraton Kasunanan Surakarta, Pengembangan Pariwisata, Penguasa Lokal Tradisional.

\section{Opportunities and Challenges of Tourism Development in the Cultural Heritage Area of the Kasunanan Surakarta Palace}

\begin{abstract}
The cultural heritage area of the Kasunanan Surakarta Palace which is called Baluwarti is a traditional settlement area which is mostly inhabited by abdi dalem and sentana dalem Kasunanan Surakarta Palace. Realizing the cultural potential they have, the community strive to develop tourism. However, for a decade, these efforts have not yielded tangible results. This research was conducted with the aim of analyzing the opportunities and challenges of tourism development in residential areas that are under the influence of traditional local authorities. A qualitative approach is used to obtain in-depth data through interviews, observations, and documentation. The selection of sources was carried out using the snowball purposive technique. Data analysis was performed using descriptive analytical methods by Miles and Huberman. This research shows that as a settlement located in the cultural heritage area of the Kasunanan Palace, Baluwarti has a lot of cultural potential. However, cultural norms and views that are strongly inherent in the Baluwarti community against the palace's cultural order, make it difficult for tourism to develop in Baluwarti. The community needs the openness of the Keraton as a role model to jointly build Baluwarti tourism so that the Palace and the community can benefit from tourism.
\end{abstract}

Keyword: Baluwarti, Kasunanan Surakarta Palace, Preserve Area, Tourism Development, Traditional Local Rulers.

\section{PENDAHULUAN}

Pariwisata diyakini sebagai agen perubahan melalui pembangunan, baik pembangunan fisik, sosial dan ekonomi (Setyaningsih, 2016). Sebagai agen pembangunan, pariwisata acapkali dianggap sebagai ancaman bagi pelestarian warisan budaya karena komoditisasi dan komodifikasi warisan budaya (Putra, 2008; Surbakti, 2008; Picard, 2009; Damanik, 2013). Paradigma tersebut telah mengalami perubahan. 
Belakangan ini banyak penelitian yang menunjukkan bahwa pariwisata bukan lagi menjadi ancaman pelestarian. Sebaliknya, pariwisata mampu menjadi sarana pelestarian warisan budaya (Timothy dan Boyd, 2003; Putra, 2008; Surbakti, 2008; Budiningtyas, 2018) dan penguatan identitas budaya masyarakat (Geertz, 2009; Bozetka, 2013; Hayward dan Kuwahara, 2013).

Masyarakat permukiman Baluwarti yang berada di kawasan cagar budaya Keraton Kasunanan Surakarta berupaya untuk mengembangkan pariwisata. Hal tersebut didorong oleh harapan untuk meningkatkan perekonomian sekaligus sebagai sarana pelestarian warisan budaya keraton. Kawasan Keraton Kasunanan Surakarta dengan permukiman tradisional Baluwarti yang berada di dalam tembok benteng keraton telah ditetapkan menjadi kawasan cagar budaya dengan SK Walikota Surakarta dengan nomor 646/1-2/1/2013 yang merupakan revisi dari SK Walikota nomor 646/116/1/1997 tentang penetapan bangunan dan kawasan kuno.

Sesuai dengan UU RI No. 11 tahun 2010 tentang Cagar Budaya menyebutkan bahwa warisan budaya harus dilestarikan dengan menerapkan prinsip perlindungan, pengembangan dan pemanfaatan. Mengingat pemeliharaan warisan budaya membutuhkan dana besar, maka warisan budaya dapat dimanfaatkan untuk mendapatkan dana pemeliharaan melalui pariwisata. Pasal 85 ayat $1 \mathrm{UU}$ RI No. 10 tahun 2009 tentang Kepariwisataan menyebutkan bahwa salah satu pemanfaatan cagar budaya adalah untuk kepentingan pariwisata. Dengan demikian sudah sepatutnya Baluwarti yang berada dalam kawasan cagar budaya Keraton Kasunanan Surakarta turut mengembangkan pariwisata demi melestarikan warisan budaya. Akan tetapi sejak tahun 2007 hingga tahun 2019, pengembangan pariwisata di Baluwarti belum menunjukkan keberhasilan. Bahkan pada tahun 2018 brand Kampung Wisata Baluwarti diciba diganti dengan Kampung Wisata Njeron Benteng (Saputro/Tribun.com, 2018). Tetapi perubahan brand tersebut tidak menampakkan hasil yang signifikan juga.

Pengembangan pariwisata yang dilakukan oleh masyarakat sejak tahun 2010 hingga saat ini tak kunjung menunjukkan hasil yang memuaskan. Oleh karena itu, penelitian ini harus dilakukan untuk melihat permasalahan yang ada di Baluwarti untuk mengurai permasalahan dan mencari jalan keluar dari permasalahan tersebut. Maka penelitian ini bertujuan untuk menganalisis peluang dan tantangan pengembangan pariwisata di permukiman Baluwarti kawasan cagar budaya Keraton Kasunanan Surakarta dan mencari jalan keluar terbaik agar pengembangan pariwisata di Baluwarti dapat terlaksana dan benar-benar memberi manfaat bagi peningkatan perekonomian masyarakat dan menjadi sarana bagi pelestarian warisan budaya.

\section{KAJIAN PUSTAKA}

Data kementerian Pariwisata Indonesia tahun 2016 menunjukkan bahwa $60 \%$ daya tarik pariwisata Indonesia adalah pariwisata budaya. Dengan demikian, wisata budaya menjadi daya tarik terbesar pariwisata di Indonesia. Warisan budaya baik yang bendawi (tangible) maupun tak-bendawi (intangible) menjadi daya tarik dalam pariwisata budaya (Timothy \& Boyd, 2003; Tuti \& Ahimsa-Putra, 2004; Picard, 2009; Damanik, 2013). Sekalipun dibedakan antara warisan budaya bendawi dan tak bendawi, tetapi sesungguhnya dalam warisan budaya bendawi terkandung makna warisan budaya tak bendawi (Timothy \& Boyd, 2003; Smith dan Akagawa, 2009; Vecco, 2010).

Definisi pariwisata warisan budaya adalah kegiatan yang dilakukan oleh orangorang untuk mengunjungi tempat-tempat bersejarah, menikmati tradisi dan kebudayaan yang ditawarkan di daerah kunjungan wisata tersebut (Timothy \& Boyd, 2003; Whyte dkk, 2012). Termasuk di antaranya adalah pertunjukan seni, hasil kerajinan tangan, gastronomi, bahasa, seni dan musik, situs bersejarah, religi, pakaian, landscape, festival (Jamieson, 2014). Warisan budaya memiliki nilai-nilai keunikan, keaslian dan keanekaragaman yang menjadi isu penting bagi wisatawan untuk mengunjungi destinasi wisata (Tuti \& Ahimsa-Putra, 2004; Picard, 2009; Damanik, 2013).

Keanekaragaman warisan budaya di Indonesia, di antaranya terbentuk karena keberadaan kerajaan-kerajaan di Indonesia dengan berbagai norma dan adat istiadatnya. Keluarga kerajaan, ceremonial terkait keluarga kerajaan, adat istiadat kerajaan, maupun tempat tinggal raja menjadi daya tarik utama bagi wisatawan untuk datang berkunjung (Setiawan, 2012; Wiweka, 2014; Palmer \& Long, 2018; Wijayanti \& Damanik, 2019). Pada umumnya, kawasan yang berdekatan dengan pusat pemerintahan tradisional seperti kerajaan, memiliki daya tarik kuat bagi pengembangan pariwisata karena lekat dengan adat istiadat dan norma dari pusat pemerintahan tradisional. 
Sekalipun telah terjadi komoditisasi dan komodifikasi budaya di sekitar tempat tinggal penguasa lokal tradisional, namun keasliannya tetap dipertahankan (Cohen, 1988; Putra, 2008). Komodifikasi yang tetap memelihara keaslian, keunikan, dan mempertahankan nilai-nilai budaya tidak dapat disebut komodifikasi, namun lebih pada pengembangan kreativitas (Budiningtyas, 2018). Setyaningsih (2016) menemukan bahwa pariwisata telah menjadi penyebab terjadinya perubahan fungsi bangunan di kawasan cagar budaya permukiman Laweyan dan Baluwarti. Tetapi Baluwarti lebih kuat mempertahankan keaslian arsitektur bangunan cagar budaya dibandingkan Laweyan.

Latar belakang sosial budaya turut mempengaruhi laju perubahan sebagai dampak pembangunan pariwisata. Laweyan memiliki latar belakang ekonomi sosial budaya sebagai saudagar batik sedangkan Baluwarti berlatar belakang budaya kerajaan yakni para abdi dalem, bupati nayaka, prajurit dalem, sentana dalem (kerabat raja) dan putra dalem (Budiningtyas, 2018). Penguasa lokal tradisional seperti keraton, masih memiliki pengaruh kuat bagi masyarakat yang tinggal di kawasan tersebut. Pada umumnya, kawasan permukiman cagar budaya yang masih memiliki orientasi kuat pada penguasa lokal tradisional cenderung lebih mempertahankan warisan budaya. Dengan demikian, penguasa lokal tradisional dapat mempengaruhi keberhasilan atau kegagalan pengembangan pariwisata di kawasan sekitarnya (Setiawan, 2012; Wiweka, 2014).

\section{METODE PENELITIAN}

Penelitian ini menggunakan metode penelitian kualitatif dengan data etnografi. Pengumpulan data dilakukan dengan cara wawancara mendalam pada narasumber menggunakan pedoman wawancara terbuka dan terstruktur. Narasumber dipilih dengan teknik snowball purposive yakni pada aparat kelurahan, ketua LPMK, ketua PPKWB (Panitia Pengembangan Kampung Wisata Baluwarti), ketua Pokdarwis, dan tokoh masyarakat setempat maupun keluarga keraton yang membidangi pariwisata.

Kelengkapan data hasil wawancara diperkuat dengan pengamatan, pustaka, dan dokumentasi. Data yang diperoleh dari hasil wawancara, pengamatan, dan dokumentasi tersebut kemudian dikelompokkan, direduksi, dan dianalisis yang kemudian dipaparkan secara naratif. Berdasarkan analisis tersebut kemudian ditarik kesimpulan.
Penelitian ini dilakukan di kelurahan Baluwarti yang merupakan permukiman tradisional yang berada di kawasan cagar budaya Keraton Kasunanan Surakarta. Permukiman Baluwarti di batasi oleh tembok benteng keraton yang memiliki ketebalan $2 \mathrm{~m}$ dan ketinggian $6 \mathrm{~m}$. Nama Baluwarti berasal dari kata baluarte dalam bahasa Portugis yang berarti benteng.

\section{HASIL DAN PEMBAHASAN}

Banyak destinasi wisata di Indonesia yang masih bercirikan kerajaan atau penguasa lokal tradisional. Jembrana, Ubud, Gianyar, Singaraja, Badung, Buleleng, Klungkung, Tabanan dan Bangli di Bali. Yogyakarta dengan Kasultanan Ngayogyakarta dan Kadipaten Paku Alaman. Surakarta dengan Kasunanan Surakarta dan Kadipaten Mangkunegaran, Cirebon dengan keraton Kasepuhan dan Kanoman, serta masih banyak lagi. Kerajaan-kerajaan tersebut menjadi pusat daya tarik pariwisata bagi daerah di sekitarnya. Sekalipun pusat-pusat kerajaan tersebut menjadi daya tarik besar bagi wisatawan (Setiawan, 2012; Wiweka, 2014; Palmer \& Long, 2018; Wijayanti \& Damanik, 2019) namun juga memiliki pengaruh kuat yang mengikat masyarakat untuk tetap melestarikan keaslian budaya yang dimiliki (Setiawan, 2012; Wiweka, 2014) dan mempertahankan identitasnya (Geertz, 2009; Bozetka, 2013; Hayward dan Kuwahara, 2013).

\section{Daya Tarik Pariwisata Baluwarti}

Permukiman Baluwarti berada dalam pemerintahan Kelurahan Baluwarti yang dikelilingi tembok benteng keraton. Kawasan ini memiliki 4 (empat) pintu gerbang yang disebut kori/lawang gapit (pintu gapit) yakni gerbang yang memiliki 2 (dua) daun pintu yang tinggi dan berat. Gerbang yang terletak di sisi Utara disebut Kori Bajranala Lor yang letaknya segaris dengan Siti Hinggil dan alun-alun Utara. Gerbang di sisi Selatan disebut Kori Bajranala Kidul yang letaknya segaris dengan Siti Hinggil dan alun-alun Selatan. Selain gerbang utama di sisi Utara dan Selatan, terdapat pintu gerbang di sisi Timur yang disebut Kori Batulan Wetan. Gerbang di sisi Barat disebut Kori Batulan Kulon. Selain gerbang-gerbang tersebut, terdapat beberapa akses pintu keluar masuk Baluwarti yang disebut butulan yang hanya dapat dilalui sepeda motor, sepeda, atau becak.

Seperti permukiman tradisional pada umumnya, nama kampung di Baluwarti dinamai menurut nama pangeran yang tinggal 
di daerah tersebut, kelompok pekerjaan, dan fungsi bangunan utama di daerah tersebut. Misalnya Mlayakusuman adalah tempat tinggal pangeran Mlayakusuma. Tamtaman adalah daerah tempat tinggal prajurit Tamtama, atau Hordenasan sebagai tempat penyimpan kuda.

Menyadari keunikan dan potensi budaya yang dimiliki, penduduk Baluwarti berupaya mengembangkan potensinya sebagai daya tarik pariwisata dengan kesadaran bahwa pariwisata mampu memperkuat nilai-nilai yang dimiliki Baluwarti, termasuk penguatan budaya dan ekonomi. Pada tahun 2012 setelah memenangi lomba tata kelurahan se-Surakarta sebagai juara ketiga, jajaran pemuka masyarakat, LPMK, dan pihak kelurahan mengajukan hibah dengan membentuk kepanitian yang diberi nama Panitia Persiapan Kampung Wisata Baluwarti (PPKWB).

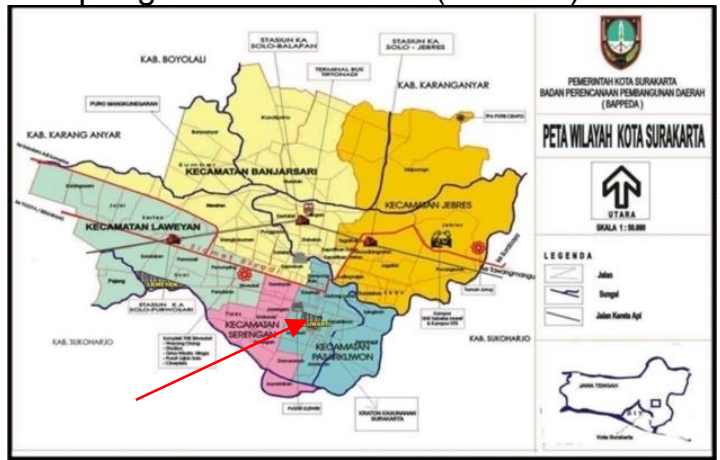

Sumber: Bappeda Surakarta, 2014

Gambar 1. Permukiman Baluwarti dalam peta Kota Surakarta

Adapun daya tarik pariwisata budaya Baluwarti adalah sebagai berikut:

\section{Kuliner}

Beras kencur, ampyang, Jenang Suran yang khusus disajikan pada malam satu Sura, Nasi liwet sebagai sajian wajib saat malam Tirakatan Ziarah Ki Gede Sala, Mentho, geplak jahe, penyon, ledre endhog (telur).

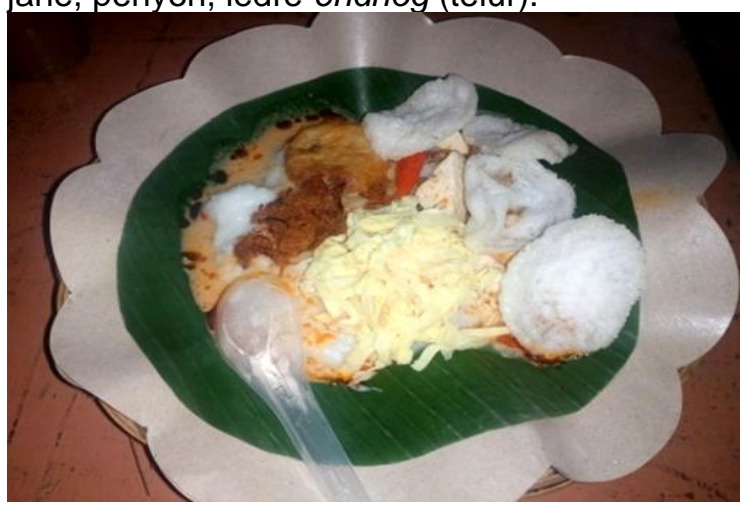

Sumber: Dokumentasi Penelitian, 2018

Gambar 2. Jenang Suran Baluwarti

\section{Bangunan Bersejarah}

Sebagai kawasan cagar budaya, maka Baluwarti memiliki banyak bangunan bersejarah yang telah dinyatakan sebagai bangunan cagar budaya. Bangunan-bangunan bersejarah tersebut adalah (1) Masjid Gambuhan yang merupakan masjid keraton yang diperuntukkan bagi abdi dalem; (2) ndalem Mangkubumen dahulu merupakan tempat tinggal putra yang telah dipersiapkan sebagai putra mahkota yang diberi gelar Mangkubumi; (3) ndalem Purwodiningratan adalah tempat tinggal sementara Sunan PB II setelah pindah dari Kartasura ke Surakarta saat keraton masih dalam tahap penyelesaian pembangunan; (4) ndalem Suryo Hamijayan: pernah menjadi tempat penyelenggaraan PON I untuk bidang olah raga tenis di lapangan tanah. Sampai sekarang lapangan tenis tersebut masih ada. Tempat ini juga menjadi tempat lahirnya sendratari Ramayana Prambanan. Saat ini ndalem Surya Hamijayan telah berpindah kepemilikan menjadi milik keluarga Cendana sejak masa ibu Tien Soeharto masih hidup; (5) ndalem Sasonomulya adalah tempat tinggal resmi putra mahkota dan pendhapa Sasonomulyo dikelola keraton. Sasonomulyo pernah menjadi tempat pentas seni PKJT (Pusat Kesenian Jawa Tengah) yang akhirnya berubah menjadi Taman Budaya Surakarta dan juga digunakan berlatih oleh ASKI (Akademi Seni Karawitan Indonesia) yang sekarang menjadi ISI (Institut Seni Indonesia) Surakarta; (6) Masjid Suronatan adalah masjid yang diperuntukkan bagi abdi dalem ulama penasehat raja; (7) ndalem Mlayakusuman adalah tempat tinggal Pangeran Mlayakusumo yang menjadi penasehat spiritual raja dan juru kunci keraton; (8) Makam Ki Gede Sala. Ki Gede Sala adalah pemilik tanah perdikan yang dipilih untuk mendirikan Keraton Kasunanan Surakarta; (8) Gondorasan adalah pawon (dapur) keraton tempat menyiapkan sesaji dan menanak nasi untuk upacara adat keraton. Berasal dari kata ganda (aroma) dan rasa (rasa); (9) ndalem Ngabeyan adalah tempat kediaman Pangeran Hangabehi yang saat ini telah berpindah kepemilikan menjadi milik keluarga Cendana; (10) ndalem Brotodiningratan atau Purwahamijayan pernah menjadi tempat tinggal $P B X$. Hingga saat ini kamar dan tempat tidur PB $X$ masih dipertahankan keasliannya dan menjadi daya tarik bagi wisatawan; (11) Lumbung Silayur adalah lumbung kuno tempat penyimpanan hasil bumi milik keraton. 


\section{Seni Karawitan dan Seni Pedalangan}

Terhimpun dalam paguyuban Sekar Budaya. Termasuk di dalamnya adalah Laras Madya, Santi swara dan Macapatan. Terdapat pula seni pedalangan di ndalem Purwadiningratan.

\section{Seni Tari}

Seni budaya menjadi daya tarik terbesar Baluwarti. Sebagai kawasan yang banyak dipengaruhi tata nilai kerajaan, maka seni budaya sangat berkembang di Baluwarti. Banyak penduduknya yang terlibat dalam kegiatan seni budaya keraton. Akan tetapi tata nilai yang berlaku tidak memperkenankan tarian istana ditarikan di luar keraton tanpa seijin kerabat raja, maka para pelaku seni di luar keraton berekreasi menciptakan tarian baru yang berorientasi pada tarian keraton. Tarian tersebut antara lain (1) Tari Anila Prahasta yang merupakan petikan dari cerita Ramayana yang menggambarkan pertempuran antara kebajikan yang diwakili Anila, melawan angkara murka yang digambarkan oleh Prahasta; (2) Tari Sesaji Sekar Delima/Melati yang terinspirasi dari tarian Bedaya atau Srimpi yang merupakan tarian sakral dalam keraton. Nama Sekar Delima atau Melati tergantung pada bunga yang dipakai sebagai bunga tabur. Tarian ini menggambarkan persembahan bagi sang pencipta dan biasa ditarikan pada acara malam Tirakatan Ziarah Ki Gede Sala.

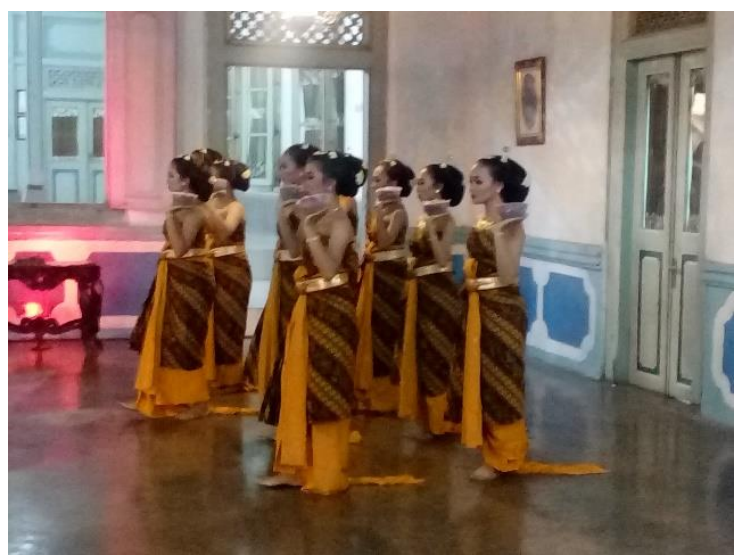

Sumber: Dokumentasi Penelitian, 2018

Gambar 3. Tari Sesaji Sekar Delima/Melati

\section{Even Budaya}

Setelah mencanangkan diri sebagai Kampun Wisata Budaya, maka PPKWB menyelenggarakan even budaya yaitu: (1) Suraloka yang diselenggarakan bertepatan dengan malam 1 Sura. Pertama kali even Suraloka terselenggara pada tahun 2010. Tetapi pada tahun 2017, adalah even Suroloka terakhir yang diselenggarakan (Budiningtyas, 2018). Hal ini karena Suraloka dipandang tidak berhasil karena tidak ada peminat yang hadir. Dalam even Suraloka juga ditampilkan Sendratari Arjuna Wiwaha yang sedianya diharapkan mampu sejajar dengan Sendratari Ramayana; (2) Malam Tirakatan Ziarah Ki Gede Sala. Ki Gede Sala adalah pemilik perdikan tempat dibangunnya Keraton Kasunanan Surakarta. Makamnya berada dekat ndalem Mlayakusuman. Pada even tersebut didaraskan Syahadat Kures atau Syahadat Sultan Agung, yakni syahadat yang menggunakan bahasa Jawa.

\section{Ketoprak dan Wayang Beber.}

ayang Beber adalah salah satu jenis wayang yang dimainkan oleh seorang dalang. Nama Beber karena cara memainkannya dengan dibeber (dibentangkan) karena terbuat dari lembaran-lembaran kain putih yang diberi gambar adegan-adegan kisah pewayangan seperti kisah Ramayana atau Mahabharata.

\section{Tantangan Pengembangan Pariwisata di Baluwarti}

Kedekatan dengan keraton yang saat ini juga menjadi daya tarik utama pariwisata Kota Surakarta, ternyata tidak berimbas bagi pariwisata yang dikembagkan oleh masyarakat Baluwarti. Sejak tahun 2011, upaya pengembangan pariwisata di Baluwarti tak kunjung membuahkan hasil yang diharapkan. Banyaknya potensi warisan budaya yang ada di Baluwarti, tidak serta merta membuat Baluwarti terangkat perekonomiannya melalui pariwisata. Terdapat beberapa kendala yang dihadapi seperti tampak pada penjelasan berikut ini.

\section{Keterbatasan Lahan}

Baluwarti, sesuai makna katanya yang berarti benteng, adalah lapisan kedua Keraton Kasunanan Surakarta yang dibatasi dengan tembok benteng setinggi 6 meter dan setebal 2 m. Untuk masuk ke kawasan Baluwarti, terdaat 4 (empat pintu gerbang) dan beberapa pintu butulan seperti yang telah disampaikan sebelumnya. Tembok beteng yang membatasi tersebut menyebabkan tidak tersedianya lahan umum yang terbuka kecuali di depan Kamandungan yaitu pintu utama keraton. Kendaraan yang dapat memasuki kawasan Baluwarti adalah kendaraan roda empat seperti mobil, motor, becak, andong, atau truk kecil. Kendaraan besar seperti bus, tidak dapat memasuki kawasan Baluwarti. Dengan demikian, lahan parkir untuk kendaraan besar 
berada di kawasan benteng Vastenburg, sekitar 500 m dari Baluwarti.

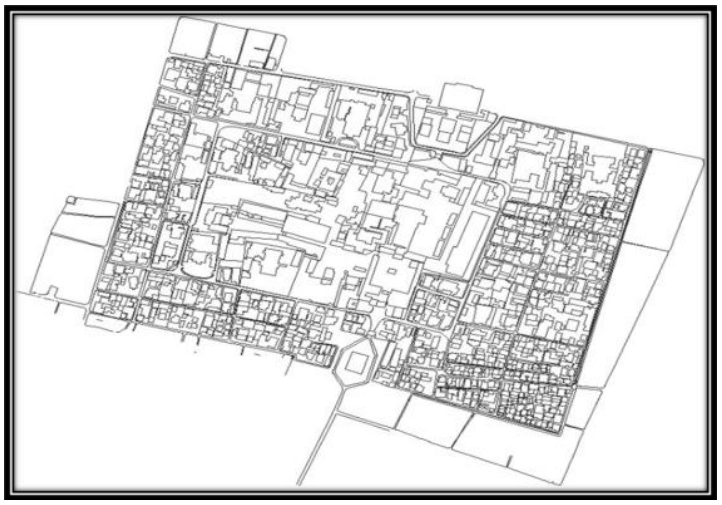

Sumber: PPKWB Baluwarti, 2016

Gambar 4. Batas Beteng dan Sebaran Bangunan di Baluwarti

Gambar di atas menunjukkan area permukiman Baluwarti yang sekelilingnya dibatasi tembok benteng dan menampakkan permukiman padat. Area yang masih tampak kosong adalah lingkaran dalam keraton yang dibatasi benteng pertama.

\section{Kepemilikan Tanah}

Hasil penelitian Budiningtyas (2018) menjelaskan bahwa penduduk Baluwarti tidak dapat mengembangkan bangunan rumah tanpa seijin pihak keraton. Hal ini dikarenakan kepemilikan tanah di Baluwarti adalah milik pihak keraton (Isbandiyah, 2008). Keraton memiliki hukum tradisional terkait pemakaian lahan dan Bangunan di Baluwarti yaitu Palilah Griya Pasiten dan perjanjian (Isbandiyah, 2008). Mengenai perjanjian, menurut Isbandiyah hanya berlaku untuk perjanjian kontrak yang tidak menimbulkan banyak persoalan. Munculnya persoalan adalah pada pelaksanaan Palilah Griya Pasiten yang terdiri dari Palilah Griya Pasiten Anggadhuh, Palilah Griya Pasiten Magersari, dan Palilah Griya Pasiten Tenggan.

Lebih lanjut dijelaskan bahwa terdapat 5 kelompok pemakaian tanah keraton yakni: (1) paringan dalem adalah tanah yang diberikan kepada putra raja dengan ketentuan sesuai ketentuan paugeran keraton dalem. Tanah boleh dijual, dengan tawaran pertama kepada keraton; (2) anggadhuh run tumurun adalah tanah yang diberikan kepada sentana dalem, bupati nayaka, prajurit, atau abdi dalem dan boleh ditempati anak keturunannya dengan catatan tanah tidak diperkenankan diperjualbelikan; (3) anggadhuh adalah tanah yang diberikan kepada sentana dalem, bupati nayaka, prajurit, atau abdi dalem yang tidak diturunkan; (4) Magersari adalah ijin untuk menempati tanah di sekitar rumah pangeran yang tidak boleh dirubah sesuai dengan aturan pangeran yang memiliki tanah tersebut; (5) Tenggan adalah abdi dalem yang ditugasi menunggu rumah pangeran yang dalam keadaan tanpa pemilik hingga raja menetapkan siapa pangeran yang berhak menempati rumah tersebut.

Pemakaian tanah tersebut harus membayar uang sewa yang disebut dhudhuk lumpur kepada pihak keraton. Penduduk yang menempati lahan juga harus membayar PBB kepada pemerintah sehingga terkesan membayar pajak ganda. Bantuan pemerintah terkait RTLH (Rumah Tidak Layak Huni) tidak dapat menjangkau penduduk Baluwarti. Hal ini disebabkan penduduk Baluwarti tidak memiliki sertifikat tanah sebagai persyaratan memperoleh bantuan tersebut (Budiningtyas, 2018). Masyarakat Baluwarti tidak banyak merubah bangunan untuk digunakan sebagai tempat usaha karena status tanah adalah tanah sewa kepada keraton dan aturan sewa yang tidak diijinkan merubah bangunan tanpa ijin pihak keraton.

Penggerak pariwisata Baluwarti, baik PPKWB maupun Pokdarwis berusaha mengemas wisata Baluwarti dengan menampilkan rumah-rumah pangeran atau bangunan-bangunan bersejarah lainnya. Namun jika akan mengunjungi rumah pangeran, maka terkendala pada tuan rumah yang menempati bangunan tersebut, termasuk masalah ijin dari tuan rumah.

\section{Pelapisan Sosial Tradisional}

Permukiman Baluwarti pada awalnya adalah permukiman tempat para abdi dalem, bupati nayaka (jabatan dalam pemerintahan kerajaan), prajurit, sentana dalem (kerabat raja), dan putra dalem (anak raja) yang kesemuanya memiliki keterkaitan dengan raja yang disebut Sunan sebagai kepala pemerintahan. Dalam tatanan tradisional kerajaan, stratifikasi tersebut menunjukkan hubungan darah, jabatan dan pekerjaan yang ditunjukkan dengan pemberian gelar-gelar tradisional oleh raja. Gelar-gelar yang diberikan raja mengandung suatu pelapisan sosial tradisional yang mengikat pemilik gelar tersebut.

Lingkungan fisik di Baluwarti menunjukkan pelapisan sosial yang sangat nyata. Secara fisik, pelapisan sosial tersebut tampak pada bangunan keraton, rumah pangeran, rumah bupati nayaka, dan rumahrumah sederhana milik prajurit serta abdi dalem yang tampak sangat mencolok perbedaannya. Pelapisan sosial terwujud pula 
dalam relasi sosial di kalangan masyarakat Baluwarti. Bahasa Jawa halus (krama inggil) yang penuh dengan norma dan menunjukkan tatanan sosial digunakan dalam pertemuan pengurus Kelurahan. Keterbukaan dalam menyampaikan pendapat terkendala pada pelapisan sosial berdasarkan gelar kebangsawanan sehingga menghambat kinerja PPKWB dan pariwisata Baluwarti. Masyarakat Baluwarti masih terikat pada norma-norma sopan santun yang kenta (Budiningtyas, 2018)I.

Status sosial dengan gelar kebangsawanan di lingkungan Baluwarti melekat dengan sikap hormat kepada yang dituakan sehingga menyebabkan masingmasing pihak saling menunggu. Dalam menyampaikan pendapat seringkali terhambat karena budaya ewuh pakewuh (sungkan/tidak enak hati) masih kuat. Hal ini karena masyarakat Baluwarti masih sangat berorientasi pada keraton, baik secara ekonomi, budaya, dan spiritual. Sekalipun secara legalitas, keraton sudah tidak lagi memiliki kekuasaan, namun kenyataannya, keluarga keraton masih sangat berpengaruh pada masyarakat Baluwarti (Budiningtyas, 2018).

Pada umumnya penduduk Baluwarti menyadari bahwa Baluwarti identik dengan keraton. Keraton dengan segala norma dan adat istiadat budayanya menjadi identitas bagi masyarakat Baluwarti. Keahlian penduduk Baluwarti dalam berolah seni tradisional tidak terlepas dari peranan keraton sebagai panutan dalam berolah seni. Keraton mampu menjadi pengikat identitas masyarakat Baluwarti yang akan membedakannya dari daerah lain (Geertz, 2009; Bozetka, 2013; Hayward dan Kuwahara, 2013).

\section{Konflik Internal Keraton}

Sejak surutnya Sri Susuhunan Paku Buwana XII pada tahun 11 Juni 2004, Keraton Kasunanan Surakarta tidak pernah berhenti dari konflik internal terkait suksesi pemerintahan Keraton Kasunanan. Sekalipun konflik tersebut terjadi di dalam tubuh keraton, tetapi secara tidak langsung berimbas pada masyarakat Baluwarti. Konflik tersebut menyulitkan masyarakat untuk menentukan langkah pendekatan dengan pihak keraton. Harapan masyarakat untuk bersinergi dengan pihak keraton dalam mengembangkan pariwisata Baluwarti menjadi terhambat karena masyarakat bingung menentukan siapa yang tepat dan memiliki kewenangan sebagai pemangku pariwisata Keraton Kasunanan Surakarta.

\section{Keraton, Baluwarti dan Pariwisata}

Berdasarkan data dinas pariwisata Kota Surakarta 2019 menunjukkan bahwa Keraton Kasunanan masih menjadi daya tarik utama wisatawan ke Kota Surakarta. Dengan demikian, Kearton Kasunanan menjadi pusat daya tarik wisata bagi Baluwarti. Dalam penjelasan sebelumnya disebutkan bahwa salah satu tantangan pengembangan pariwisata di Baluwarti adalah kuatnya orientasi penduduk Baluwarti pada keraton baik secara ekonomi, budaya dan spiritual..

Secara ekonomi, masih banyak penduduk Baluwarti yang sekalipun memiliki pekerjaan lain, tetapi sekaligus mereka adalah abdi dalem. Sebagai abdi dalem, maka terikat secara spiritual bahwa aturan raja dan perkataan raja adalah yang utama. Keyataan bahwa tanah yang ditempati adalah milik Sunan, membuat penduduk tidak dapat mengembangkan usaha tanpa ijin dari pihak keraton. Kepemilikan tanah keraton tersebut diperkuat dengan Keputusan Presiden No. 23 tahun 1988, pada masa pemerintahan Presiden Soeharto. Berdasarkan keputusan tersebut, kepemilikan tanah oleh keraton menjadi semakin kuat. Jika masyarakat ingin menggunakan tanah keraton yang ditempati sebagai tempat usaha, maka satu-satunya jalan adalah dengan mengajukan permohonan ijin kepada keraton agar dapat memanfaatkan lahan milik keraton yang ditempati.

Selain orientasi ekonomi, keraton juga menjadi orientasi spiritual. Para abdi dalem tidak berani melakukan hal-hal yang dilarang keraton, termasuk mementaskan tarian keraton. Larangan pihak keraton menjadi suatu hukum tidak tertulis yang mengikat secara spiritual. Oleh karena itu para pekerja seni di Baluwarti mengembangkan kreativitas dengan mengembangkan tarian yang berorientasi pada tarian keraton.

Kreativitas sangat diperlukan dalam mengembangkan pariwisata. Kekuatan kreativitas pelaku seni di Baluwarti karena memiliki kedekatan dengan keraton yang sangat mempengaruhi keterampilan seni dan pandangan budaya masyarakat. Pada satu sisi, keraton memberikan dorongan bagi masyarakat untuk berkreasi, namun pada sisi lain, konflik yang terjadi dalam tubuh Keraton Kasunanan menyebabkan masyarakat bingung menentukan arah pada siapa akan melakukan pendekatan untuk bersama-sama mengembangkan pariwisata di Baluwarti sekaligus menjadi sarana pelestarian budaya dan penguat identitas budaya.

Pemerintah telah berupaya mencari penyelesaian konflik yang terjadi dalam tubuh 
Keraton Kasunanan. Namun berbagai upaya yang telah dilakukan tidak banyak membuahkan hasil. Keraton, dalam hal ini Sunan sebagai kepala pemerintahan memiliki otonomi untuk mengelola harta miliknya atau mengambil tindakan penyelesaian konflik. Konflik di dalam tubuh keluarga Keraton Kasunanan adalah konflik keluarga yang bahkan pemerintah tidak dapat masuk campur tangan dalam penyelesaiannya (Tempo.co, 2017; Sholikah, 2019).

\section{PENUTUP}

Tidak dapat dipungkiri bahwa di banyak destinasi wisata budaya, pusat-pusat pemerintahan tradisional atau keraton/ puri/ pura memiliki daya tarik yang luar biasa bagi wisatawan. Hal ini menyebabkan kawasan di sekitarnya turut mendapat imbas dari daya tarik tersebut. Dampak kedekatan dengan pusat pemerintahan tradisional yang menjadi daya tarik wisata budaya dapat berupa dampak ekonomi, sosial, dan budaya. Pusat pemerintahan tradisional seperti keraton, memiliki daya tarik kuat karena lekat dengan adat istiadat dan norma budaya dari pusat pemerintahan tradisional yang sekaligus menjadi identitas bagi masyarakat di sekitarnya.

Baluwarti sebagai kawasan yang berada sangat dekat dengan keraton memiliki kekayaan warisan budaya yang beraneka ragam. Para pekerja seni di Baluwarti memiliki kreativitas dalam mengolah seni sehingga tetap mampu menampilkan nilai-nilai luhur budaya Jawa tanpa menyentuh hal sakral yang tidak diijinkan oleh pihak keraton. Namun kelekatan masyarakat Baluwarti yang memiliki orientasi kuat pada keraton baik secara ekonomi, budaya dan spiritual, menjadi sebuah hambatan dalam mengembangkan pariwisata budaya. Oleh karena itu masyarakat berharap pihak keraton mau membuka diri dan bersama dengan masyarakat mengembangkan wisata Baluwarti, sekalipun tetap akan ada pembatasan dengan tradisi keraton yang hanya boleh dilakukan pihak keraton.

Pada tahun 2011 Baluwarti memenangkan juara tiga lomba tata kelurahan dan mencanangkan program Baluwarti sebagai Kampung Wisata berbasis kearifan lokal. Saat itu masyarakat menindaklanjuti dengan mengundang pihak-pihak terkait seperti Pamangku Pariwisata Keraton Kasunanan, dinas pariwisata Kota Surakarta dan tokoh masyarakat Baluwarti untuk duduk bersama memikirkan pengembangan pariwisata Baluwarti (Budiningtyas, 2018). Akan tetapi pertemuan tersebut tidak berlanjut pada tahap implementasi pengembangan pariwisata secara sinergi antara pihak keraton dengan masyarakat Baluwarti.

Hambatan pencapaian kemajuan pariwisata di Baluwarti disebabkan oleh kesulitan dinas terkait untuk menembus kekuasaan tradisional keraton. Banyak program dari pemerintah gagal terlaksana karena untuk merealisasikan program pemerintah diperlukan prosedur perijinan pihak Keraton Kasunanan dan persyaratanpersyaratan yang tidak dapat dipenuhi oleh penduduk setempat. $\mathrm{Hal}$ ini disebabkan lingkungan Kelurahan Baluwarti adalah permukiman tradisional yang masih terikat dengan penguasa tradisional keraton yang memiliki otonomi untuk mengelola tanah miliknya (Isbandiyah, 2008) . Masyarakat Baluwarti berharap konflik di dalam tubuh keraton segera berakhir dan pihak keraton bersedia membuka diri untuk bersama-sama mengembangkan pariwisata Baluwarti dengan Keraton Kasunanan sebagi pusat daya tarik kelurahan Baluwarti yang berada dalam kawasan cagar budaya Keraton Kasunanan Surakarta.

Dapat disimpulkan bahwa kedekatan dengan pusat pemerintahan tradisional selain memberikan kekayaan warisan budaya yang berpotensi untuk dikembangkan sebagai daya tarik wisata, ternyata juga memiliki banyak hambatan. Hasil dari penelitian ini dapat dijadikan sebagai bahan acuan dalam penelitian sejenis. Hal ini karena di Indonesia banyak terdapat kawasan-kawasan yang berada di lingkungan pusat kerajaan dengan kondisi yang kurang lebih sama, yakni sebagai orientasi budaya dan spiritual, memiliki norma dan adat istiadat yang masih dipegang kuat, kepemilikan lahan, serta pelapisan sosial tradisional.

\section{DAFTAR PUSTAKA}

Artha, A. T., dan Ahimsa-Putra, H. S. (ed). (2004). Jejak Masa Lalu: Sejuta Warisan Budaya. Yogyakarta: Kunci IImu

Bozetka, B. (2013). "Wolin Island, Tourism and Conception of Identity". Journal of Marine and Island Cultures. 2, 1-12.

Budiningtyas, E. S. (2018). Pariwisata dan Pelestarian Warisan Budaya Berbasis Kearifan Lokal di Kota Surakarta. Disertasi. Yogyakarta: Universitas Gadjah Mada. 
Damanik, J. (2013). Pariwisata Indonesia: Antara Peluang dan Tantangan. Yogyakarta: Pustaka Pelajar.

Geertz, C. (2009). "Cultural Tourism: Tradition, Identity and Heritage Construction", dalam Wiendu Nuryanti (ed), The Role of Heritage Tourism in Community Planning and Development. Yogyakarta: Gadjah Mada University Press. 26-34.

Hayward, P. \& Kuwahara, S. (2013). "Divergent Trajectories: Environment, Heritage and Tourism in Tanegashima, Mageshima and Yakushima". Journal of Marine and Island Cultures, 2, 2938.

Isbandiyah, K. (2008). Kebijakan Karaton Surakarta Hadiningrat dalam Pengelolaan Tanah dan Bangunan setelah Keputusan Presiden Nomor 23 Tahun 1988 tentang Status dan Pengelolaan Keraton Kasunanan Surakarta di Kelurahan Baluwarti Kota Surakarta. Tesis. Semarang: Universitas Diponegoro.

Jamieson, W. (2014). Cultural Heritage Tourism Planning and Development: Defining the Field and Its Challenges. APT Bulletin, Vol. 29, No. 3/4, 65-67.

Palmer, N. \& Long, P. (2018). The Peculiar Attraction of Royalty for Tourism and the Social Construction of 'Royal Tourism'. Researchgate, June.

Picard, M. (2009). "Cultural Tourism in Bali", dalam W. Nuryanti (ed), The Role of Heritage Tourism in Community Planning and Development. Yogyakarta: Gadjah Mada University Press. 176-190.

Putra, A. M. (2008). "Identitas dan Komodifikasi Budaya dalam Pariwisata Budaya Bali". Jurnal Analisis Pariwisata Vol. 8 (2). Fakultas Pariwisata Universitas Udayana, 7-16.

Saputra. (2018). Kelurahan Baluwarti Solo Tawarkan Wisata Kuno di Dalam Benteng Keraton Kasunanan Surakarta. Tribun.com. Diakses 05 Januari 2019. https://solo.tribunnews.com/2018/12/0 8/kelurahan-baluwarti-solo-tawarkanwisata-kuno-di-dalam-bentengkeraton-kasunanan-surakarta

Setiawan, I. K. (2012). Pusaka Budaya Pura Tirta Empuldan Pengembangan
Pariwisata. PUSTAKA, Vo. XII, No. 1 (Februari), 98-106.

Setyaningsih, W. (2016). "Transformasi Arsitektural dari Kampung Kota menjadi Kampung Wisata: Studi Kasus Kampung Wisata di Surakarta". Disertasi. Yogyakarta: Fakultas Teknik Universitas Gadjah Mada.

Smith, L dan Akagawa, N. (2009). Intangible Heritage. New York: Routledge.

Sholikah, B. (2019). Keraton Solo Kisruh Lagi, Pemerintah Diminta Turun Tangan. Republika.co.id: diakses 25 Januari 2021.

https://nasional.republika.co.id/berita/p xcn9r320/keraton-solo-kisruh-lagipemerintah-diminta-turun-tangan

Surbakti, A. (2008). "Komodifikasi Budaya Populer dalam Pariwisata". Jurnal Anilisis Pariwisata Vol. 8 (2) ISSN 1410-3729. Fakultas Pariwisata Universitas Udayana, 17-24.

Timothy, D. J. \& Boyd, S. W. (2008). Heritage Tourism in 21st Century: Valued Traditions and New Perspectives. Journal of Heritage Tourism, Vol 1. No. 1, 1-17.

Vecco, M. (2010). A Definition of Cultural Heritage: From the fangible to the intangible. Journal of Cultural Heritage, 11, 321-324.

Wiweka, K. (2014). Analisis Konsep Tri Hita Karana pada Daya Tarik Warisan Budaya: Studi Kasusu Puri Agung Karangasem, Bali. JUMPA, Vol. 1. No. 1 (Juli), 139-160.

Whyte, B., Hood, T., dan White, BP (ed). (2012). Cultural and Heritage Tourism a Handbook for Community Champions. Canada: Federal Provincial Territorial Ministers of Culture and Heritage.

Pemerintah Indonesia. 2009. Undang-undang No. 10 Tahun 2009 tentang Pariwisata.

Pemerintah Indonesia. 2010. Undang-undang No 11 Tahun 2010 tentang Cagar Budaya.

Tempo.co. (2017). Konflik Keraton Solo, Tjahjo: Pemerintah Menyerahkan ke PB XIII. Diakses 25 Januari 2021. https://nasional.tempo.co/read/868706/ konflik-keraton-solo-tjahjo-pemerintahmenyerahkan-ke-pb-xiii/full\&view=ok 